\title{
Evaluation of the major royal jelly proteins as an alternative to fetal bovine serum in culturing human cell lines*
}

\author{
Di CHEN, Xiao-xuan XIN, Hao-cheng QIAN, Zhang-yin YU, Li-rong SHEN ${ }^{\dagger *}$ \\ (Department of Food Science and Nutrition, Fuli Institute of Food Science, Zhejiang Key Laboratory for Agro-Food Processing, \\ Zhejiang University, Hangzhou 310058, China) \\ †E-mail: shenlirong@zju.edu.cn
}

Received Nov. 28, 2015; Revision accepted Feb. 2, 2016; Crosschecked May 12, 2016

\begin{abstract}
Royal jelly $(R J)$ is a well-known bioactive substance. It contains large amounts of major royal jelly proteins (MRJPs), which express growth-factor-like activity in several animal and human cell lines. However, the question on whether MRJPs possess growth-factor-like activity on all types of cell cultures remains. In order to determine whether MRJPs can be used as an alternative to fetal bovine serum (FBS) in different types of human cell culture, the proliferation of the complex serum with different ratios of MRJPs/FBS (M/F) was evaluated on five cell lines: 293T, HFL-I, 231, HCT116, and Changliver using MTT (3-(4,5-dimethyl-2-thiazolyl)-2,5-diphenyl-2H-tetrazolium bromide) assay. The proliferation activity of the combination of the complex M/F serum with cytokines on the test cell lines was also measured. The results demonstrated that the complex serum with $M / F$ 6/4 possessed the highest proliferation activity similar to or in excess of FBS. However, no activity of complex medium with M/F 6/4 was observed in 231 cells, indicating a selectivity of MRJPs on cell types. Compared with the complex medium with M/F 6/4, the complex medium with M/F 6/4 together with two cytokines, epidermal growth factor (EGF) and insulin-transferrin-selenium (ITS), promoted proliferations of Changliver, 293T, HCT116, and HFL-I by $18.73 \%-56.19 \%(P<0.01)$. Our findings demonstrate that MRJPs could partially replace FBS in culturing many human cell lines.
\end{abstract}

Key words: Major royal jelly proteins (MRJPs), Cell culture, Alternative, Fetal bovine serum (FBS), Cytokine http://dx.doi.org/10.1631/jzus.B1500295 CLC number: Q253; S896.3

\section{Introduction}

Royal jelly (RJ), a principal food of the honeybee queen and larvae of worker bees, is secreted at the hypopharyngeal and mandibular glands by nurse honeybees. Due to its richness in bioactive substances, RJ has been widely used as a popular and traditional supplement for health promotion (Shen et al., 2010). Notably, about $50 \%$ of the dry mass of $\mathrm{RJ}$ is made of proteins (Malecova et al., 2003), of

\footnotetext{
¿ Corresponding author

* Project supported by the National Natural Science Foundation of China (No. 31271848), the Important Scientific \& Technical Innovation Project of Hangzhou (No. 20131812A25), and the Foundation of Fuli Institute of Food Science of Zhejiang University (No. KY201404), China

(D) ORCID: Li-rong SHEN, http://orcid.org/0000-0002-3197-9245

(C) Zhejiang University and Springer-Verlag Berlin Heidelberg 2016
}

which $80 \%-90 \%$ belong to major royal jelly proteins (MRJPs) (Schmitzová et al., 1998). Nine members of the MRJP family (49-87 kDa) have been identified in $\mathrm{RJ}$ produced by the Western honey bee (Apis mellifera) (Drapeau et al., 2006). MRJP1 that constitutes $48 \%$ of MRJPs (Simúth, 2001) is the most abundant protein in RJ. MRJPs usually are in the form of an oligomeric structure (Buttstedt et al., 2014). It was shown that the monomeric form of MRJP1 shortened the developmental time of larvae, and increased body mass and ovary size. However, these effects were not observed with the oligomeric form of MRJP1. MRJP1 was proved to be the key factor of caste differentiation in the honeybee (Kamakura, 2011).

In addition to the function as a nutritive protein (Kupke et al., 2012), the MRJPs possess growthfactor-like activity in several animal and human cell 
lines and have potential to replace the fetal bovine serum (FBS), which is widely used in the cell culture medium as a supplement. The usage of FBS faces both moral and scientific obstacles because of the limited sources, the composition changes between batches, and possible contamination from viruses, mycoplasm and prions (EL-Ensahsy et al., 2009). For this reason, development of alternatives to replace FBS is essential, particularly for cell culture purposes. Hence, more investigations to evaluate the activities of RJ or RJ proteins have been carried out (Karaca et al., 2012; Musa et al., 2013). Kimura et al. (2003) found that $350-\mathrm{kDa} \mathrm{RJ}$ glycoprotein stimulates proliferation of human monocytes. Kimura et al. (1996) found that $55-\mathrm{kDa}$ RJ glycoportein (RJGP) maintains the high viability of the rat liver primary cultured cell and is a different molecular species from $350-\mathrm{kDa}$ RJGP. Fifty-seven-kDa protein stimulated the growth of five human lymphocytic cell lines (U-937, THP-1, U-M, HB4C5, HF10B4) in serum-free conditions and arrested the cell to the Gl phase (Watanabe et al., 1996). MRJP1 also enhances hepatocyte DNA synthesis and stimulates the proliferation of primary cultured rat hepatocytes, as well as increasing albumin production (Kamakura et al., 2001). RJ crude protein extracts stimulated cell growth of Tn-5B1-4 insect cells compared with FBS (Salazar-Olivo and Paz-Gonzalez, 2005).

However, the question of whether MRJPs possess growth-factor-like activity in all types of cell cultures remains. For example, a recent investigation showed that RJ extract does not exhibit the activity in MRC-5 cells, human fibroblast cells (Musa et al., 2013). In addition, differential effects of MRJPs in combination with different cytokines on cell viability remain unclear. Therefore, in this study we examined the effects of the MRJPs in combination with different cytokines as an alternative to FBS at different ratios of MRJPs/FBS (M/F) on the viabilities of different types of human cell lines.

\section{Materials and methods}

\subsection{Main reagents and instruments}

Avariant of human embryonic kidney 293 cell (293T) was obtained from Shanghai Yancheng Biotechnology Co., Ltd., China. Human embryonic lung fibroblast (HFL-I) was obtained from Sun Yat-sen University (Guangzhou, China). Human breast cancer cell (231), human colon cancer cell (HCT116), and Changliver cell were donated by Prof. Bo YANG's laboratory of Zhejiang University (Hangzhou, China) and Xiamen Overseas Chinese Subtropical Plant Introduction Garden (Xiamen, China). The MTT (3(4,5-dimethyl-2-thiazolyl)-2,5-diphenyl-2H-tetrazolium bromide) assay kit was supplied by Nanjing Keygen Biotech. Co., Ltd. FBS (Hyclone), Dulbecco's modified Eagle's medium (DMEM), Leibovitz's L15, and RPMI-1640 were supplied by Gino Biotechnology Co., Ltd., Hangzhou, China; epidermal growth factor (EGF) was from Prime Gene, Shanghai, China, insulintransferrin-selenium (ITS) was from ScienCell, Buckingham, UK, and dexamethasone (DSMS) was from Kingyork, Tianjin, China. All biochemical reagents were of highest purity commercially available. DSZ5000X inverted system microscope was from Chongqing UOP photoelectric technology Co., Ltd. and a Multiskan MK microplate reader was from Thermo Fisher (Shanghai, China).

Fresh RJ was provided by Hangzhou Biyutian Health Food, Co., Ltd. (Hangzhou, China) and stored at $-80{ }^{\circ} \mathrm{C}$ until use. An RJ crude protein (RJCP) was extracted and diluted in phosphate buffered saline (PBS) by centrifugation at $12000 \mathrm{~g}$ for $30 \mathrm{~min}$ under $4{ }^{\circ} \mathrm{C}$ according to the method previously reported (Salazar-Olivo and Paz-Gonzalez, 2005). Then MRJPs were obtained from RJCPs dialyzed against 500 volumes of $\mathrm{ddH}_{2} \mathrm{O}$ via being distilled using a 1000-Da cutoff dialysis membrane at $4{ }^{\circ} \mathrm{C}$ (Salazar-Olivo and Paz-Gonzalez, 2005). The concentration of MRJPs was determined via the method of Bradford (1976) using bovine serum albumin as the standard. The presence of proteins in MRJPs was analyzed by sodium dodecyl sulphate-polyacrylamide gel electrophoresis (SDS-PAGE).

\subsection{Assay of different proportions of MRJPs and FBS on cell proliferation}

MRJP solution was diluted with PBS to the concentration of $5 \mathrm{mg} / \mathrm{ml}$. The complex M/F serum consisting of $5 \mathrm{mg} / \mathrm{ml} \mathrm{MRJPs} \mathrm{(M)} \mathrm{and} \mathrm{FBS} \mathrm{(F)} \mathrm{was}$ prepared in the following proportions: $\mathrm{M} / \mathrm{F} 0 / 10, \mathrm{M} / \mathrm{F}$ 3/7, M/F 6/4, M/F 9/1. The growth-promoting activities of all the complex M/F serums were measured by MTT assay (Yang et al., 2013). In brief, logarithmic 
growth phase cells $\left(1 \times 10^{4}\right.$ cells $\left./ \mathrm{ml}\right)$ suspended in $100 \mu \mathrm{l}$ culture medium were inoculated into 96 -well plates containing $10 \%(\mathrm{v} / \mathrm{v})$ of complex $\mathrm{M} / \mathrm{F}$ serum. Cells were maintained at $37^{\circ} \mathrm{C}$ in a humidified environment with $5 \% \mathrm{CO}_{2}$. Then the viability of cells was detected according to the kit over the following days. 293T, HFL-I, and HCT116 were cultured with the medium of DMEM. 231 and Changliver were cultured with the medium of L15 and RPMI-1640, respectively.

\subsection{Proliferation assay of the cytokine combina- tion added in $\mathrm{M} / \mathrm{F}$ serum on five human cell lines}

The culture medium contained combinations of seven cytokines as follows: EGF, ITS, DSMS, EGF+ITS, EGF+DSMS, ITS+DSMS, and EGF+ ITS+DSMS, which were added to the culture medium with $10 \%$ complex $\mathrm{M} / \mathrm{F} 6 / 4$ serum based on a proliferation test. According to the providers' instructions, the final concentrations of cytokines, EGF, DSMS, and ITS in the medium were $20 \mathrm{ng} / \mathrm{ml}$, $50 \mu \mathrm{g} / \mathrm{ml}$, and $10 \mathrm{ng} / \mathrm{ml}$, respectively. The growthpromoting activity was detected by the method described above.

\subsection{Statistical analysis}

The data were analyzed using Data Processing System (DPS) statistical software. One-way analysis of variance (ANOVA) was used to evaluate differences between each group. The values are reported as mean \pm standard deviation (SD) and $P$-value of $<0.05$ was considered significant.

\section{Results}

\subsection{Composition of MRJPs}

The protein concentration of MRJP solutions determined by Bradford assay was $12.61 \mathrm{mg} / \mathrm{ml}$. SDS-PAGE analysis of MRJPs showed four main protein bands ranging from 49 to $77 \mathrm{kDa}$ in molecular weight, which are identified as MRJP5, MRJP3, MRJP1, and MRJP2, respectively (Fig. 1) according to the previous work (Shen et al., 2015).

\subsection{Proliferative effects of the complex $\mathrm{M} / \mathrm{F}$ serum on four human cell lines}

The media supplemented with FBS (positive control), M/F 3/7, M/F 6/4, M/F 9/1, and PBS (negative

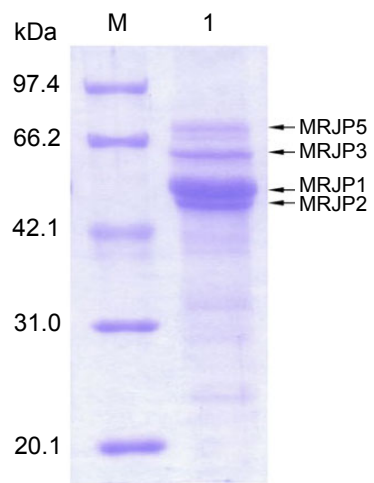

Fig. 1 SDS-PAGE analysis of MRJPs used in culturing test cell lines

Lanes of M and 1 refer to protein marker and MRJPs, respectively

control) produced relative cell viabilities (absorbance) of $0.44,0.68,0.59,0.48$, and 0.18 , respectively, in $293 \mathrm{~T}$ cells on the 5th day. Compared with the positive control (FBS), the complex M/F 3/7, M/F 6/4, and $\mathrm{M} / \mathrm{F} 9 / 1$ increased the cell viability by $55.59 \%$, $34.53 \%$, and $9.72 \%$, respectively (Table 1 ). The media supplemented with FBS, M/F 3/7, M/F 6/4, M/F 9/1, and PBS produced relative cell viabilities of 1.46 , $1.37,1.42,0.63$, and 0.15 in HCT116 cells on the 5th day, respectively (Table 1). Compared with FBS, the complex M/F 6/4 showed no significant difference in cell viability, and $\mathrm{M} / \mathrm{F} 3 / 7$ and $\mathrm{M} / \mathrm{F} 9 / 1$ serum resulted in a significant decrease $(P<0.01)$ in cell viability (Table 1). The media supplemented with FBS, M/F 3/7, M/F 6/4, M/F 9/1, and PBS produced relative cell viabilities of $0.66,0.66,0.73,0.56$, and 0.40 in HFL-I cells on the 8th day, respectively. Compared with FBS, the complex M/F 6/4 showed a significant increase $(P<0.01)$ in cell viability by $10.65 \%, \mathrm{M} / \mathrm{F} 9 / 1$ resulted in a significant decrease $(P<0.01)$, and $\mathrm{M} / \mathrm{F}$ $3 / 7$ showed no significant effect on cell viability (Table 1). Moreover, most of the test cells, e.g. 293T and HCT116 lines in the mixture of M/F 6/4 and FBS, were in a healthy condition and stuck to the plates well, and had a higher density compared with the same test cells in the medium with FBS (Fig. 2). However, most cells in M/F 9/1 with lower FBS content did not stick to the plate well, and most cells in PBS were in poor health and spread in culture in a cluster form. These results demonstrate that the complex M/F 6/4 serum with higher MRJP content increased cell viability, and was considered as the best alternative to FBS in cell cultures of 293T, HCT116, and HFL-I. 
Table 1 Effects of M/F ratios on the proliferation in 293T, HCT116, 231 (on Day 5), and HFL-I (on Day 8)

\begin{tabular}{|c|c|c|c|c|c|c|}
\hline \multirow{2}{*}{ Cell line } & \multicolumn{5}{|c|}{ Absorbance } & \multirow{2}{*}{$P$-value } \\
\hline & FBS & $\mathrm{M} / \mathrm{F} 3 / 7$ & $\mathrm{M} / \mathrm{F} 6 / 4$ & M/F 9/1 & PBS & \\
\hline $293 \mathrm{~T}$ & $0.44 \pm 0.11^{b}$ & $0.68 \pm 0.06^{\mathrm{a}}$ & $0.59 \pm 0.03^{\mathrm{a}}$ & $0.48 \pm 0.04^{b}$ & $0.18 \pm 0.05^{\mathrm{c}}$ & 0.0047 \\
\hline HCT116 & $1.46 \pm 0.04^{\mathrm{a}}$ & $1.37 \pm 0.03^{b}$ & $1.42 \pm 0.03^{\mathrm{a}}$ & $0.63 \pm 0.04^{\mathrm{c}}$ & $0.15 \pm 0.02^{\mathrm{d}}$ & 0.079 \\
\hline $231(\times 10)^{*}$ & $2.36 \pm 0.18^{\mathrm{a}}$ & & $0.81 \pm 0.02^{b}$ & & $0.52 \pm 0.06^{\mathrm{c}}$ & $<0.0001$ \\
\hline HFL-I $(\times 10)$ & $0.66 \pm 0.03^{b}$ & $0.66 \pm 0.03^{b}$ & $0.73 \pm 0.02^{\mathrm{a}}$ & $0.56 \pm 0.01^{\mathrm{c}}$ & $0.40 \pm 0.07^{\mathrm{d}}$ & 0.0498 \\
\hline
\end{tabular}

${ }^{*} \times 10$ : values are expressed as 10-fold absorbance. Absorbance means denoted with the same letter $(\mathrm{a}-\mathrm{d})$ in the same row do not differ significantly from each other. Data are expressed as mean $\pm \mathrm{SD}(n=3,4)$
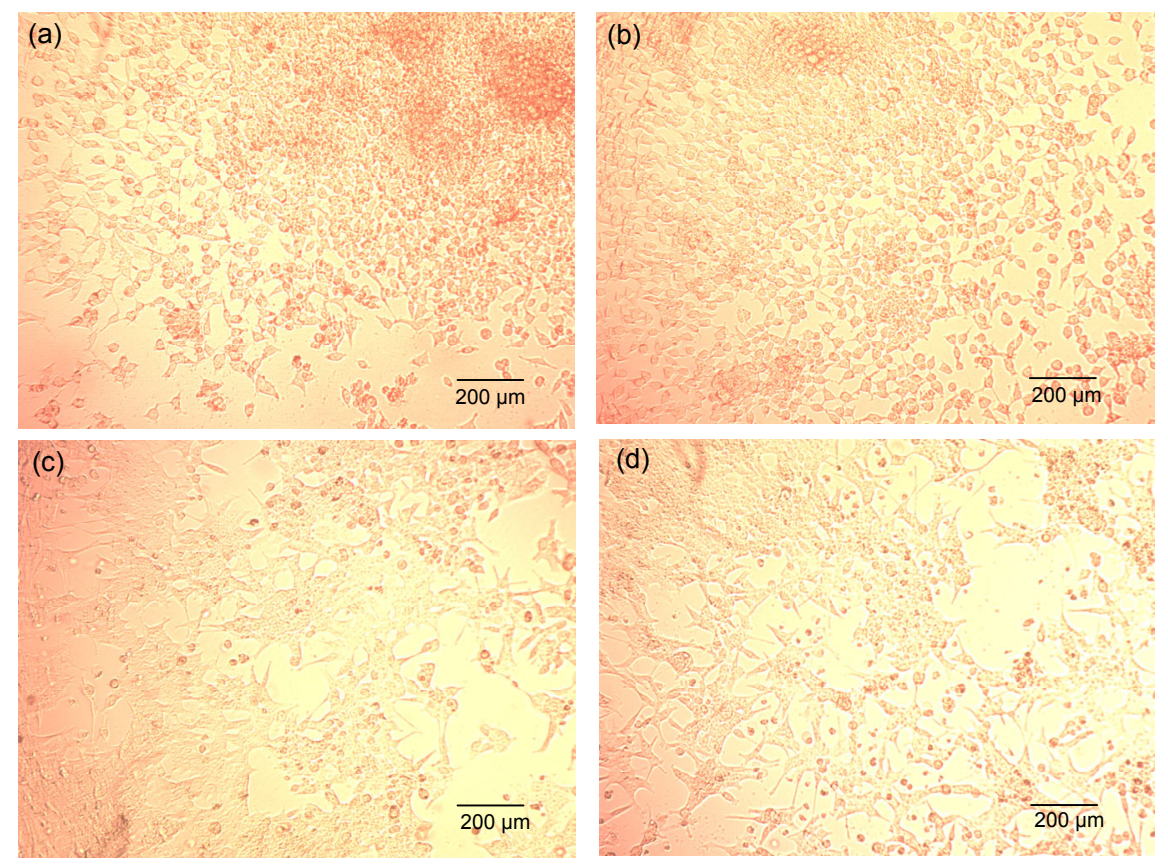

Fig. 2 Cellular morphology of 293T and HCT116 (on Day 5) treated by the complex M/F 6/4 serum and FBS, respectively (a) $293 \mathrm{~T}+\mathrm{FBS}$; (b) $293 \mathrm{~T}+\mathrm{M} / \mathrm{F}$ 6/4; (c) HCT116+FBS; (d) HCT116+M/F 6/4

On the other hand, in the cell line 231, all media supplemented with different MRJPs showed little effect on cell viability compared with FBS (Table 1). The cells in complex M/F 6/4 serum, which showed better viability for other three test cell lines, 293T, HCT116, and HFL-I as above, could not stick to the plate. Hence, MRJPs are not suitable for culturing this cell line (i.e. 231 ) in replacement of FBS. As the complex M/F 6/4 serum showed significant cell proliferation for three test cell lines, 293T, HCT116, and HFL-I, its proportion was applied in the following tests.

\subsection{Effects of cytokines added in complex $\mathrm{M} / \mathrm{F}$ serum on five human cell lines}

3.3.1 Effects of cytokines on Changliver and 231 cells

231 and Changliver cells were cultured with different combinations of cytokines (EGF, ITS, and
DSMS) based on the complex M/F 6/4 serum. The media supplemented with FBS, complex M/F serum (FM), FM+ITS+EGF+DSMS (FMIED), FM+EGF+ DSMS (FMED), FM+ITS+EGF (FMIE), FM+ITS+ DSMS (FMID), FM+EGF (FME), FM+ITS (FMI), and FM+DSMS (FMD) produced relative cell viabilities of $0.23,0.08,0.09,0.08,0.10,0.10,0.08,0.09$, and 0.08 in 231 cells on the 3rd day, respectively (Fig. 3a). Compared with FM, FMIE and FMI increase cell viability by $19.38 \%$ and $13.21 \%$, respectively $(P<$ 0.01). The media supplemented with FM, FMIED, FMED, FMIE, FMID, FME, FMI, and FMD produced relative cell viabilities of $0.18,0.19,0.19,0.26$, $0.17,0.23,0.21$, and 0.14 , respectively, in Changliver cell on the 3rd day. Compared with FM, FMIE, FME, and FMI increase cell viability by $39.89 \%, 27.12 \%$, and $17.64 \%$, respectively $(P<0.01$; Fig. $3 b)$. 

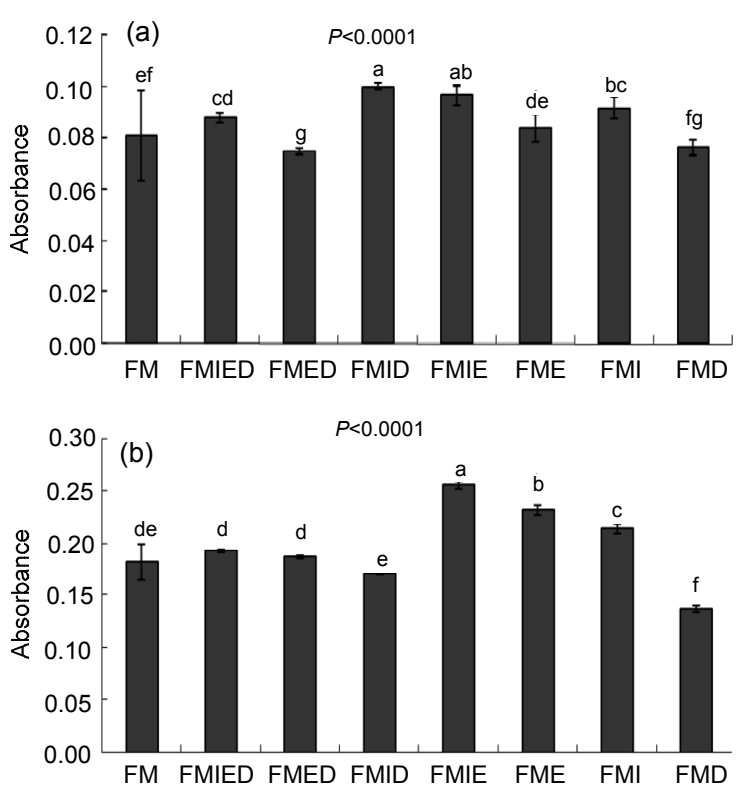

Fig. 3 Effects of several cytokines together with the complex $M / F$ 6/4 serum on the proliferations of 231 (a) and Changliver (b) cells (on Day 3)

The means of absorbance denoted with the same letter $(\mathrm{a}-\mathrm{g})$ do not differ significantly from each other. Data are expressed as mean $\pm \mathrm{SD}(n=3,4)$

The test cells, e.g. Changliver cell line, in the medium of FMIE showed better health and stuck to the plate well, and were at a higher density (Fig. 4b) than that in the FM medium (Fig. 4a). This evidence suggests that complex $\mathrm{M} / \mathrm{F} 6 / 4$ serum together with ITS+EGF possesses a higher activity to promote proliferation for both 231 and Changliver cells.

\subsubsection{Effects of cytokines on 293T and HCT116 cells}

The media supplemented with FM, FMIE, FME, and FMI produced relative cell viabilities of 0.70 , $0.84,0.74$, and 0.77 in $293 \mathrm{~T}$ cell on the 3rd day, respectively (Fig. 5a). Compared with FM, FMIE, FME, and FMI increased cell viability by $18.73 \%, 4.83 \%$ and $9.10 \%$, respectively, which suggests that $\mathrm{M} / \mathrm{F} 6 / 4$ serum with added EGF+ITS possesses a higher activity in promoting proliferation in the $293 \mathrm{~T}$ cells.

The media supplemented with FM, FMIE, FME and FMI produced relative cell viabilities of 0.40 , $0.51,0.37$, and 0.42 , respectively, in HCT116 cells on the 5th day. Compared with FM, FMIE and FMI increase cell viability by $25.11 \%$ and $3.53 \%$, respectively (Fig. 5b), suggesting that M/F 6/4 serum with added EGF+ITS possesses a higher activity in promoting proliferation in the HCT116 cells.
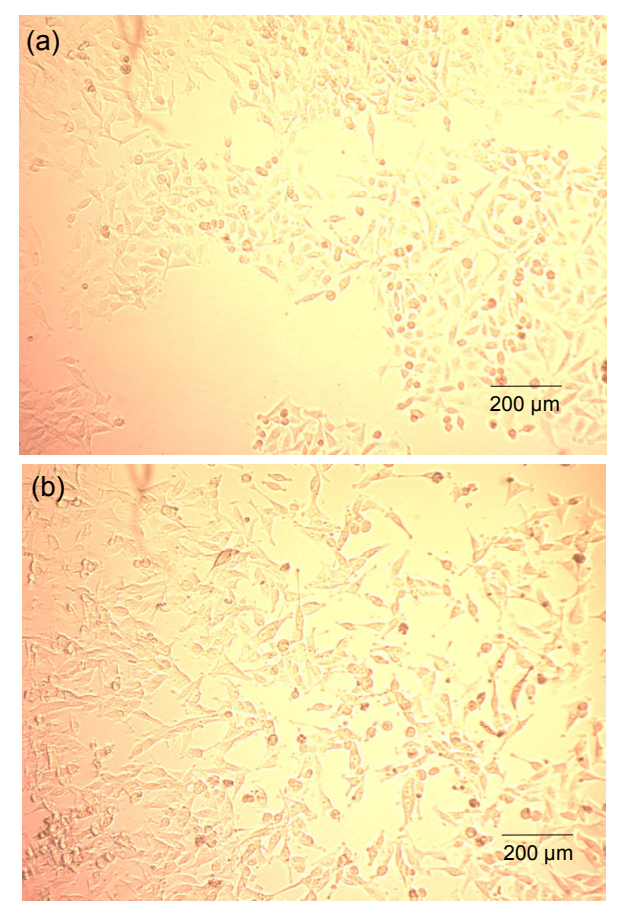

Fig. 4 Cellular morphology and densities of Changliver (on Day 3) cultured with complex M/F 6/4 serum (FM) and the combination of FM and cytokines ITS+EGF (FMIE), respectively

(a) Changliver+FM; (b) Changliver+FMIE
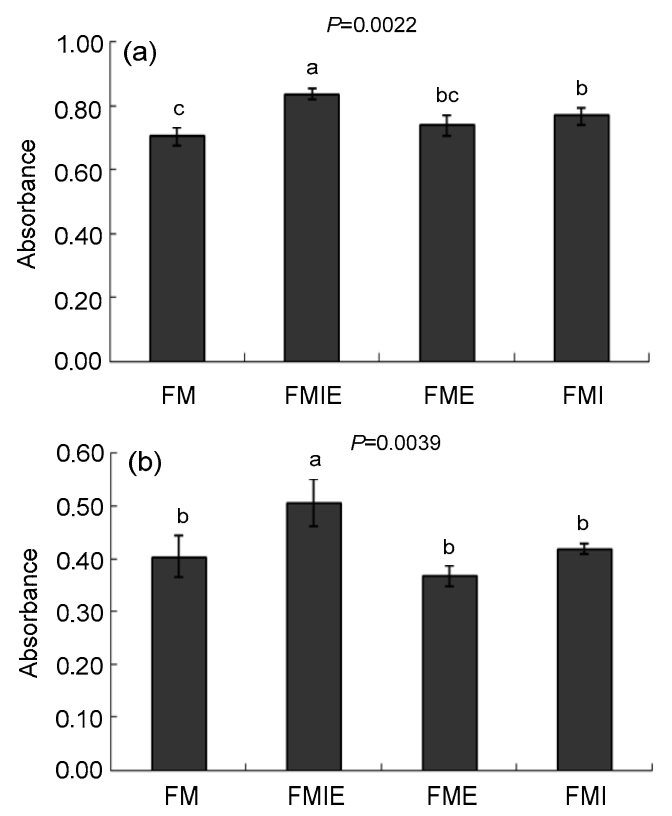

Fig. 5 Effects of combinations of cytokines together with the complex M/F 6/4 serum on the proliferation of 293T cells (a) (on Day 3) and HCT116 cells (b) (on Day 5)

The means of absorbance denoted with the same letter $(\mathrm{a}-\mathrm{c})$ do not differ significantly from each other. Data are expressed as mean $\pm \mathrm{SD}(n=3,4)$ 


\subsubsection{Effects of cytokines on HFL-I cells}

The media supplemented with FM, FMIE, FME, and FMI produced relative cell viabilities of 0.06 , $0.09,0.07$, and 0.08 in HFL-I cells on the 10th day, respectively. Compared with FM, FMIE, FME, and FMI increased cell viability by $56.19 \%, 20.29 \%$, and $35.91 \%$, respectively (Fig. 6), which suggests that $\mathrm{M} / \mathrm{F}$ 6/4 serum with added EGF+ITS possesses a higher activity in promoting proliferation of the HFL-I cells.

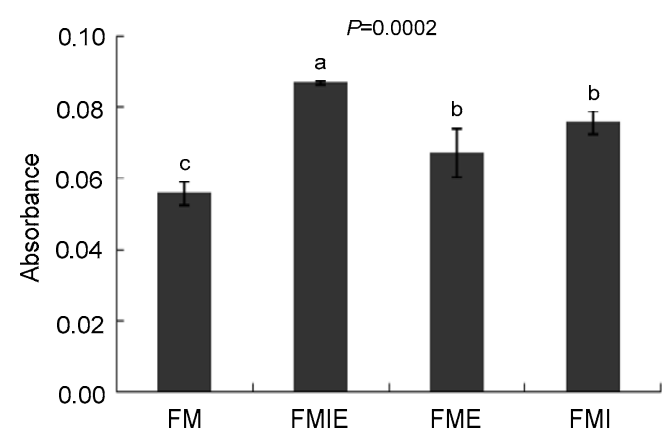

Fig. 6 Effects of combinations of cytokines together with the complex $\mathrm{M} / \mathrm{F}$ 6/4 serum on the proliferation of HFL-I cells (on Day 10)

The means of absorbance denoted with the same letter $(\mathrm{a}-\mathrm{c})$ do not differ significantly from each other. Data are expressed as mean $\pm \mathrm{SD}(n=3,4)$

\section{Discussion}

Our previous report ( $\mathrm{Yu}$ et al., 2015) showed that the complex M/F 6/4 serum exhibited the best proliferation activity on the Changliver cells. The beneficial activity is associated with the promotion of DNA synthesis in the S phase, or RNA and protein synthesis in the G0/G1 phase. However, MRJPs could not completely replace FBS to culture the cells. This investigation demonstrated further that the complex $\mathrm{M} / \mathrm{F}$ 6/4 serum possesses significant proliferation activity on three new human cell lines, 293T, HFL-I, and HCT116, but has little effect on the 231 cells, indicating selectivity of MRJPs to cell types. Also, we found that supplementing both cytokines EGF+ITS increased cell viability in four cell lines (Changliver, 293T, HFL-I, and HCT116) by $18.73 \%-56.19 \%$ compared with the complex M/F 6/4 serum. These findings demonstrate that MRJPs could partially replace FBS for culturing many human cell lines.
$\mathrm{RJ}$ extract or RJ proteins used as cell growth factors or as an alternative to FBS have been paid more attention to in cell culture (Watanabe et al., 1996; Kamakura et al., 2001). The evaluation of RJ extract or RJ proteins was implemented in several cell lines from insects, rats, and humans (Kimura Y. et al., 1996; Kimura M. et al., 2003; Salazar-Olivo and PazGonzalez, 2005). However, most previous work (Musa et al., 2013; Yu et al., 2015) focused on using single RJ extract or RJ proteins to replace FBS. The cell type and the combination formula of RJ extract or RJ proteins with FBS and cytokines have been neglected (Musa et al., 2013). In addition, more evidence has shown that MRJPs, especially MRJP1, are the key active factors for honeybee cast variation and larvae development, and animal and human cells. Thus, more research on the purification and qualification of RJ extract or crude RJ proteins is needed. A lower temperature is essential to maintain the activity of MRJPs. The exposure of RJ extract to $25 \mathrm{kGy} \gamma$ radiation may be the main cause of RJ loss of cell growth activity in the report of Musa et al. (2013). In our investigation, the protocols of the extract, purification, and qualification of MRJPs have been standardized, which could ensure objective results in culture cells.

In order to improve the activity of the complex $\mathrm{M} / \mathrm{F}$ serum, three cytokines, EGF, ITS, and DMSM, were tested in different combinations (Papeleu et al., 2004; Kurita et al., 2013; Chen et al., 2014; Mimura et al., 2015). The results showed that the combination of EGF+ITS with the complex M/F 6/4 serum increased cell viability significantly in four cell lines, Changliver, 293T, HFL-I, and HCT116. However, the complex $\mathrm{M} / \mathrm{F}$ serum still has limitations in being used in cell culture as an alternative to FBS. Thus, more cell lines should be investigated. These findings have provided new evidence to develop new usages of RJ.

\section{Conclusions}

We demonstrated that MRJPs were able partially to replace FBS in culturing human cells, and complex $\mathrm{M} / \mathrm{F}$ 6/4 serum promoted the proliferation of cells with selectivity. Based on the complex M/F 6/4 serum, adding cytokines increased cell viability. These findings provide new evidence to develop new usages of 
$\mathrm{RJ}$ in future. However, the growth-factor-like activity of the complex $\mathrm{M} / \mathrm{F} 6 / 4$ serum should be screened extensively in more cell lines, and the mechanism corresponding to the activity should be further investigated.

\section{Acknowledgements}

The authors are grateful to Prof. You-ying TU (Zhejiang University, Hangzhou, China) for her technical assistance, and Dr. Chao-qiang LAI (JM-USDA HNRCA at Tufts University, USA) for editing the manuscript.

\section{Compliance with ethics guidelines}

Di CHEN, Xiao-xuan XIN, Hao-cheng QIAN, Zhang-yin YU, and Li-rong SHEN declare that they have no conflict of interest.

This article does not contain any studies with human or animal subjects performed by any of the authors.

\section{References}

Bradford, M.M., 1976. A rapid and sensitive method for the quantitation of microgram quantities of protein utilizing the principle of protein-dye binding. Anal. Biochem., 72(1-2):248-254. http://dx.doi.org/10.1016/0003-2697(76)90527-3

Buttstedt, A., Moritz, R.F., Erler, S., 2014. Origin and function of the major royal jelly proteins of the honeybee (Apis mellifera) as members of the yellow gene family. Biol. Rev., 89(2):255-269.

http://dx.doi.org/10.1111/brv.12052

Chen, G., Yue, A., Ruan, Z., et al., 2014. Human umbilical cord-derived mesenchymal stem cells do not undergo malignant transformation during long-term culturing in serum-free medium. PLoS ONE, 9(6):e98565. http://dx.doi.org/10.1371/journal.pone.0098565

Drapeau, M.D., Albert, S., Kucharski, R., et al., 2006. Evolution of the Yellow/Major Royal Jelly Protein family and the emergence of social behavior in honey bees. Genome Res., 16(11):1385-1394.

http://dx.doi.org/10.1101/gr.5012006

EL-Ensahsy, H.A., Abdeen, A., Abdeen, S., et al., 2009. Serum concentration effects on the kinetics and metabolism of HeLa-S3 cell growth and cell adaptability for successful proliferation in serum free medium. World Appl. Sci. J., 6(5):608-615.

Kamakura, M., 2011. Royalactin induces queen differentiation in honeybees. Nature, 473(7348):478-483. http://dx.doi.org/10.1038/nature10093

Kamakura, M., Suenobu, N., Fukushima, M., 2001. Fiftyseven-kDa protein in royal jelly enhances proliferation of primary cultured rat hepatocytes and increases albumin production in the absence of serum. Biochem. Biophys. Res. Commun., 282(4):865-874. http://dx.doi.org/10.1006/bbrc.2001.4656
Karaca, T., Simsek, N., Uslu, S., et al., 2012. The effect of royal jelly on $\mathrm{CD}^{+}, \mathrm{CD}^{+}, \mathrm{CD} 45^{+} \mathrm{T}$-cell and $\mathrm{CD} 68^{+}$cell distribution in the colon of rats with acetic acid-induced colitis. Allergol. Immunopathol., 40(6):357-361. http://dx.doi.org/10.1016/j.aller.2011.09.004

Kimura, M., Kimura, Y., Tsumura, K., et al., 2003. 350-kDa royal jelly glycoprotein (apisin), which stimulates proliferation of human monocytes, bears the $\beta 1-3$ galactosylated $\mathrm{N}$-glycan: analysis of the $\mathrm{N}$-glycosylation site. Biosci. Biotechnol. Biochem., 67(9):2055-2058. http://dx.doi.org/10.1271/bbb.67.2055

Kimura, Y., Kajiyama, S., Kanaeda, J., et al., 1996. N-linked sugar chain of 55-kDa royal jelly glycoprotein. Biosci. Biotechnol. Biochem., 60(12):2099-2102. http://dx.doi.org/10.1271/bbb.60.2099

Kupke, J., Spaethe, J., Mueller, M.J., et al., 2012. Molecular and biochemical characterization of the major royal jelly protein in bumblebees suggest a non-nutritive function. Insect Biochem. Mol. Biol., 42(9):647-654. http://dx.doi.org/10.1016/j.ibmb.2012.05.003

Kurita, R., Suda, N., Sudo, K., et al., 2013. Establishment of immortalized human erythroid progenitor cell lines able to produce enucleated red blood cells. PLOS ONE, 8(3): e59890. http://dx.doi.org/10.1371/journal.pone.0059890

Malecova, B., Ramser, J., O'Brien, J.K., et al., 2003. Honeybee (Apis mellifera L.) mrjp gene family: computational analysis of putative promoters and genomic structure of mrjp1, the gene coding for the most abundant protein of larval food. Gene, 303:165-175. http://dx.doi.org/10.1016/S0378-1119(02)01174-5

Mimura, S., Suga, M., Liu, Y., et al., 2015. Synergistic effects of FGF-2 and Activin A on early neural differentiation of human pluripotent stem cells. In Vitro Cell. Dev. Biol. Anim., 51(8):769-775. http://dx.doi.org/10.1007/s11626-015-9909-8

Musa, M., Nasir, N.F.M., Thirumulu, K.P., 2013. Evaluation of royal jelly as an alternative to fetal bovine serum in cell culture using cell proliferation assays and live cell imaging. Afr. J. Tradit. Complement. Altern. Med., 11(1): 148-155. http://dx.doi.org/10.4314/ajtcam.v11i1.23

Papeleu, P., Loyer, P., Vanhaecke, T., et al., 2004. Proliferation of epidermal growth factor-stimulated hepatocytes in a hormonally defined serum-free medium. Altern. Lab. Anim., 32(Suppl. 1A):57-64.

Salazar-Olivo, L.A., Paz-Gonzalez, V., 2005. Screening of biological activities present in honeybee (Apis mellifera) royal jelly. Toxicol. in Vitro, 19(5):645-651. http://dx.doi.org/10.1016/j.tiv.2005.03.001

Schmitzová, J., Klaudiny, J., Albert, S., et al., 1998. A family of major royal jelly proteins of the honeybee Apis mellifera L. Cell. Mol. Life Sci., 54(9):1020-1030. http://dx.doi.org/10.1007/s000180050229

Shen, L.R., Zhang, W.G., Jin, F., et al., 2010. Expression of 
recombinant AccMRJP1 protein from royal jelly of Chinese honeybee in Pichia pastoris and its proliferation activity in an insect cell line. J. Agric. Food Chem., 58(16): 9190-9197.

http://dx.doi.org/10.1021/jf1007133

Shen, L.R., Wang, Y.R., Zhai, L., et al., 2015. Determination of royal jelly freshness by ELISA with a highly specific anti-apalbumin 1 , major royal jelly protein 1 antibody. $J$. Zhejiang Univ.-Sci. B (Biomed. \& Biotechnol.), 16(2): 155-166. http://dx.doi.org/10.1631/jzus.B1400223

Simúth, J., 2001. Some properties of the main protein of honeybee (Apis mellifera) royal jelly. Apidologie, 32(1): 69-80.

http://dx.doi.org/10.1051/apido:2001112

Watanabe, K., Shinmoto, H., Kobori, M., et al., 1996. Growth stimulation with honey royal jelly DIII protein of human lymphocytic cell lines in a serum-free medium. Biotechnol. Tech., 10(12):959-962.

http://dx.doi.org/10.1007/BF00180402

Yang, F., Huang, W., Li, Y., et al., 2013. Anti-tumor effects in mice induced by survivin-targeted siRNA delivered through polysaccharide nanoparticles. Biomaterials, 34(22): 5689-5699. http://dx.doi.org/10.1016/j.biomaterials.2013.03.047

Yu, Z.Y., Chen, D., Wang, Y.L., et al., 2015. Effect of major royal jelly proteins (MRJPs) on proliferation activity of Chang's liver cell line and their mechanism of action. $J$. Zhejiang Univ. (Agric. \& Life Sci.), 41(1):7-14 (in Chinese). http://dx.doi.org/10.3785/j.issn.1008-9209.2014.03.231

\section{中文概要}

题 目: 蜂王浆主蛋白 (MRJPs) 作为灭活胎牛血清 (FBS) 替代品培养人体细胞的效果评价

目 的: 为 MRJPs 应用于人体细胞培养提供科学依据, 为 发展蜂王浆在细胞工程的新用途提供技术支撑。

创新点: 首次验证 MRJPs 对多种人体细胞的促分裂效果, 证实 MRJPs 可部分替代 FBS 培养人体细胞, 并 取得培养人体细胞的 MRJPs 与 FBS 和细胞因子 的适合比例。

方 法: 鲜蜂王浆中分离得到的 MRJPs 溶液与 FBS 按不 同比例 $(0 / 10 、 3 / 7 、 6 / 4$ 和 9/1) 复配成复合血清, 分别添加于无血清培养基中用于培养 293T、 HFL-I、231、HCT116 和 Changliver 等 5 种人体 细胞。以添加体积分数为 $10 \%$ 的 FBS 的无血清培 养基为对照, 根据 MTT 法测定的吸光度和细胞 形态比较分析结果, 得到促进细胞分裂的 MRJPs 溶液与 FBS 最佳配合比例。然后在篎选出的最佳 复合血清中添加不同的细胞因子, 再通过同样的 比较分析，得到适合的细胞因子组合。

结 论: MRJPs 对多种人体细胞具有促进分裂作用, 可部 分替代 FBS 培养人体细胞。MRJPs 与 FBS 的最 佳配比为: $60 \%$ MRJPs 溶液和 40\% FBS（复合血 清）；该复合血清与细胞因子的最佳组合为: 复 合血清+表皮生长因子+胰岛素-转铁蛋白-硒。

关键词: 蜂王浆主蛋白; 灭活胎牛血清; 细胞培养基; 替 代品; 分裂; 细胞因子 